\title{
The Violence of Uncertainty: empirical evidence on how asylum waiting time undermines refugee health
}

\author{
June 2021 \\ (Published in Social Science \& Medicine) \\ https://doi.org/10.1016/i.socscimed.2021.114154
}

Jenny Phillimore

University of Birmingham

\author{
Sin Yi Cheung \\ Cardiff University
}

\begin{abstract}
The idea of violent uncertainty was first introduced in the New England Journal of Medicine (2018) making claims about the deleterious impacts of insecure immigration status on the health of migrants. Policies of uncertainty are said to directly and indirectly create harm by impacting on individual's health via detention and public degradation and undermining healthcare services. We offer original empirical evidence indicating an association with uncertainty, in the form of asylum waiting times, on refugees' self-reported health. We devise four hypotheses that: long waiting time for asylum decisions increases likelihood of self-reported health problems and the effect persists overtime, that female refugees report higher levels of health problems and religion moderates the association between health and uncertainty. We use data from the UK longitudinal Survey of New Refugees wherein all new refugees were sent a baseline survey immediately after receiving refugee status and then follow-up surveys 21 months later. The findings show longer asylum waiting time is associated with poor health. Female refugees were more likely to report poor emotional and physical health. The negative effect of asylum waiting time on emotional health persists 21 months post settlement and is worse for women. The hypothesis about the ameliorating effect of religion is only partially supported. Our findings supports existing theory and qualitative studies on the deleterious effects of using policies of waiting-related uncertainty for managing migration. Given the wide use of such policies in the Global North, our work is suggestive of likely generalisability. Thus, countries with large refugee populations might want to consider our findings when developing asylum policy which minimises impact on refugee health.
\end{abstract}

Keywords: asylum seeker waiting time; violent uncertainty; refugee emotional health; refugee physical health; gender; religion, asylum policy; refugee integration 


\section{The Violence of Uncertainty: empirical evidence on how asylum waiting time undermines refugee health}

\section{Introduction}

Grace and colleagues (2018) introduced the idea of violent uncertainty in the New England Journal of Medicine in 2018 having witnessed the effects of state sanctioned uncertainty on migrants in the US. The deleterious impacts of policies of uncertainty on the health of individuals who lack secure immigration status have been observed across the Global North but as yet have not been quantitatively operationalised and investigated for refugees. Violent uncertainty is a form of violence inflicted on refugees and asylum-seekers "enacted through systematic personal, social and institutional instability that exacerbates inequality and injects fear into the most basic of daily interactions" (2018: 904). Government policies of uncertainty perpetuate systematic insecurity creating harm directly and indirectly. Indirect harm involves undermining trust in institutions resulting in targeted groups being fearful of accessing healthcare. Direct harm comes from policies themselves impacting on individual's mental and physical health by "undermining their security" through detention, travel bans and public degradation with systematic insecurity and fear going beyond any one institution (Grace et al., 2018). For asylum seekers in the UK this involves extended waiting for a decision on whether they will be allowed to remain that is open-ended (Brekke, 2004) keeping them in a "passive and desperate state of continual transience and uncertainty" (Griffiths, 2014: 15).

This paper offers the first empirical evidence showing the effect of asylum waiting periods (Laban et al., 2005) on refugees' self-reported emotional and physical health. In the UK, waiting is an integral part of the asylum system with the Government stating that integration cannot commence until refugee status is received (Home Office 2005, 2008). While awaiting a decision, asylum-seekers' lives are intentionally put "on hold". They are not permitted to work, have restricted access to study, are subject to travel bans, and have no possibility of family reunion. In addition, they are dispersed and re-dispersed on a no-choice basis to areas where there are high levels of deprivation (Phillimore and Goodson, 2006), where they experience racism (Lentin, 2004) and live in poor quality housing shared with strangers (Phillips, 2006). Levels of asylum support are so low that they have been referred to as a form of "slow violence" (Mayblin et al., 2020) wherein every day is consumed with the very act of survival and difficult choices are made between food, transport, medication and mobile phone data (see Phillimore et al., 2021).

Waiting for many years for an asylum decision is normal as are high levels of refusal. During the period of 2005-2007 in which the SNR was conducted, between 23,000 and 25,000 asylum seekers arrived per year. Of these around $25 \%$ were granted asylum after an initial claim. Yet even now in 2021, around $1 \%$ of applicants from that period are yet to receive an initial decision (Home Office, 2021). Movements between being "in" and "outside" the asylum system are common. When an initial decision is unsuccessful asylum seekers are classified as failed asylum seekers and are evicted from asylum housing with asylum support ceased. Those considered a flight risk may be detained. The majority of asylum seekers appeal a negative asylum decision (Lyons, 2018) with success after rates of appeal varying by country of origin but generally reaching between 40 and 50 per cent of all applicants (Walsh, 2020). In other words, seeking asylum in the UK frequently results in periods of destitution and detention and is imbued with uncertainty about the future. The UK's Home Office sets a target of giving adult applicants an initial decision within six months of claim submission with the share of applicants currently receiving a decision in this time frame around $20 \%$ (Walsh, 2020). No target is set for decision making timeframes for appeals. Thus the majority of claimants are subject to lengthy waits for a decision. Similar forms of waiting with associated uncertainty about the future are part of asylum processes across the Global North (Dupont et al., 2005; Laban et al., 2008; Lauritzen et al., 2012; Ingvarsson et al., 2016; Bjertrup et al., 2018; Cleveland et al., 2018).

Migration has long been associated with uncertainty and risk (Williams and Balaz, 2012) but forced migration and waiting for a decision about resettlement (Afifi et al., 2019) or asylum (Laban et al., 2005; Cange et al., 2019) is particularly problematic. Waiting is open-ended and takes place in a context 
of poor living conditions, the absence of distractions such as work and study, separation from family members and the threat of forced return to places of unsafety (Laban et al., 2015; Rotter, 2016; Refugee Action, 2018). There is evidence that asylum seekers and refugees experience higher levels of PTSD, anxiety and depression than the general population (Laban et al., 2005; Afifi et al., 2019; Ahmad et al., 2020; Blackmore et al., 2020) with associations identified between asylum seekers living in a "chronic state of uncertainty" (Afifi et al., 2019), psychological disorders and somatoform disorders but no evidence around relationships between waiting and physical health. As we note above asylum seekers await a decision on whether they can legitimately remain in the country of refuge. Thus waiting is core to asylum seeking and may be an important factor in generating uncertainty which has a deleterious effect on wellbeing.

The experience of waiting is described by Auyero (2011) building on Bourdieu (2000) as an act of subordination. Unclear and seemingly arbitrary processes which shape decisions (Auyero, 2011) and flawed decision-making leave asylum seekers in limbo in a state of waiting described as punitive (Rotter, 2016). Endpoints are not only uncertain and beyond the control of individuals but threaten the very survival of those who fail as they face abandonment in the form of destitution and homelessness, and/or return, at the end of processes (Chase, 2020). Yet as we note above many asylum seekers do, after many months or years, gain some kind of leave to remain. Once permission to remain is granted asylum-seekers' status changes to "refugee" and they are then encouraged to integrate into wider society. Little is known about the relationship between length of time waiting for a decision and refugee integration. Laban et al. (2005) show clear evidence of a relationship between amount of time waiting and psychological disorders in Iraqi asylum seekers. But they focus only on asylum seekers who have yet to receive a positive decision. To what extent does length of wait with its associated stresses shape refugee health post-decision when the waiting and uncertainty is over? Blackmore et al. (2020) in a meta-analysis of the prevalence of mental illness in refugees and asylum seekers show that PTSD and depression persist many years after displacement and that rates of PTSD vary in different groups and are on the increase. One possible explanation offered is increasingly harsh immigration policies including delayed granting of refugee status. Biehl (2015) too highlights "protracted uncertainty" and never-ending waiting as connected to psychological disorders.

Qualitative evidence from across Europe and Australia suggests a strong connection between the effects of policies of uncertainty and health. Inability to influence the asylum process, lack of control over one's life combined with concerns about the general population's views of asylum-seekers leaves individuals lacking self-esteem and feeling humiliated (Lauritzen and Siversten 2012; Cleveland et al., 2018). Fear of removal (Sourander, 2003) and being separated from family (Reesp, 2003), exacerbated by the absence of distractions (Lauritzen and Sivertsen, 2012) have also been reported. Uncertainty is said to have a greater impact on asylum-seekers than pre-migration trauma with Laban et al. (2005) showing that post-migration factors which included open-ended asylum processes but also the living conditions and lack of opportunities associated with asylum status were more strongly linked with psychological disorders than pre-migration trauma. The uncertainty associated with waiting and the conditions in which individuals must live while they wait have been argued to be associated with wideranging mental health problems such as depression, anxiety, psychosocial distress and suicide ideation (Dupont et al., 2005, Bronstein et al., 2013; Schoretsanitis et al., 2018). These harms are said to impede individual's ability to integrate once refugee status is received (Laban et al., 2008).

Existing work suggests there are three factors which may shape the extent to which waiting is associated with health and wellbeing. The first is time. Qualitative studies have found the longer the wait for a successful asylum decision, the greater the effect on health (Lamkaddem at al., 2015; Fleay and Hartley, 2016; Schoretsanitis et al., 2018). While quantitative studies highlight a relationship between time within the asylum system and psychological health (Laban et al., 2005) they have not explored whether there is an association between waiting times and refugee health post-decision. In Canada Ahmad et al. (2020) focus on resettlement refugees who arrive with permanent status and thus are not subject to asylum process uncertainties. They found lower rates of depression among Syrian refugees resettled in Canada compared to Syrian cohorts elsewhere. They suggest that those who have been through asylum 
processes may experience higher levels of psychological disorder because they have less certainty about their status. However they noted an increase in depression symptoms after one year of residence which may relate to in-country conditions that could include access to work and experiences of racism. Thus we propose that the length of time waiting for a decision will be associated with health at grant of refugee status. Moreover, it is likely that there will be a continued association between length of wait and health at 21 months after grant of status once refugees have regained some certainty and are permitted to work, choose where to live and study. The effects associated with waiting may have been mediated by post-asylum decision conditions in particular employment status and experiences of racism (Cheung and Phillimore, 2017).

The second is gender difference. In the general population the burden of depression and anxiety disorders are significantly higher for women than men (Kuehner, 2016; Li et al., 2016). Women refugees are also more likely to experience depression than men (Reesp, 2003; Laban et al., 2008; Ahmad et al, 2020) but also higher levels of physical health problems (Reesp, 2003; Laban et al., 2008). There is clear evidence that they experience different kinds of adversity, with sexual and gender based violence (SGBV) a reality for many women forced migrants (WRC, 2016) which Kuehner (2016) suggests may explain higher rates of depression in women in the general population. Feminist researchers point to the continuum of violence experienced by women refugees fleeing conflict which include multiple forms of sexual and gender based violence (Borges and Faria, 2020) generating gendered harms (Canning, 2018). These are often exacerbated by multiple forms of structural violence once in refuge (Phillimore et al. 2021) which may go some way to explain the gender differences in health. We hypothesise that women refugees may experience greater adverse mental and physical issues from waiting given that the conditions in which they wait have been found to be particularly problematic for women (Canning, 2018).

The third is religion with Turnbull (2016) suggesting religion protects individuals in the general population from the sometimes deleterious effects of waiting. However, Ahmad et al. (2020) find a negative correlation between Muslims and depression symptoms in Syrian refugees resettled in Canada but not Christians or other religions. Elsewhere religion is cited as a protective factor in enabling refugees' every day coping with displacement that can offer some protection from psychological disorders (i.e. Babatunde-Sowole et al., 2016; Veronese et al., 2019) and instability caused by ongoing uncertainty operating as a coping mechanism (Wu et al., 2020). It is unclear whether religious identity or practice underpin these associations though it is possible that religious practice or gatherings may provide broader social and support network resulting in better mental wellbeing. We hypothesise that individuals who identify as having a religion may experience lower mental and physical effects from waiting as religious coping may ameliorate psychological and physical health effects.

\section{Methods}

Our key empirical interest is the length of asylum claim determination time and its association with refugees' self-reported health. The data come from the Survey of New Refugees (SNR) which is the only large-scale quantitative dataset on refugee integration in the UK and one of the largest in the world. Commissioned by the UK's Home Office, the SNR is a longitudinal survey which took place between 2005 and 2007 commenced in 2005 with a baseline postal questionnaire sent one week after grant of status to 8,254 refugees aged 18 or over in 10 languages (Home Office, 2010; Cebulla et al., 2010). Three subsequent surveys were sent again by post 8,15 and 21 months later with follow-up questions enabling longitudinal analysis. The aim was to collect information on refugee characteristics when they received a positive asylum decision and their integration outcomes post-settlement. Questions covered a wide range of topics from health, housing, employment, language skills, and contact with friends and relatives. The baseline survey achieved a response rate of 70 per cent with 5,742 questionnaires returned.

As with most longitudinal surveys, the SNR suffers from high sample attrition despite efforts in tracing the respondents. The samples size dropped significantly to 1,840, 1,259 and 939 in the three follow-up surveys. The high attrition rate is likely to be a result of policy and design effect. First, upon receiving 
refugee status, asylum seekers were forced to give up their National Asylum Support Service (NASS) housing. Many may have to resort to temporary accommodation before finding somewhere permanent to live. Second, not having an address makes it impossible to receive a postal survey. This is evident since the main sample attrition occurred in the first follow-up survey where 68 percent of the respondents at baseline had dropped out. It was found that at the first follow-up survey, younger (under 25) refugees in NASS Accommodation at baseline, those from Turkey (coded as Europe), those without pre-migration qualification (that were not transferable to the UK), and those not living with a partner were more likely to drop out. By Wave 4, male refugees, those under 25 years old and with no qualifications were more likely to drop out (Cebulla et al., 2010). With this knowledge of the characteristics of the drop-outs, the SNR team developed both cross-sectional and longitudinal survey weights to mitigate the attrition problem. Following standard practice and recommendation of the data user guide, cross-sectional and longitudinal weights were applied to all statistical analyses.

In the absence of clinical data, the SNR is the best source for investigating refugee integration outcomes in the UK. It is also the only large-scale dataset enabling analysis of refugee health. It includes selfreported health measures using a 5-point Likert Scale capturing emotional and physical health separately. The health questions were items taken from the widely used Short-Form Health Survey SF8. Ideally, one would use multiple indicators to measure emotional and physical health such as the full SF-8. However, since the SNR was not a health survey, we have utilised the best available measures in the dataset. For emotional health, we have taken the question on whether participants were feeling worried, depressed and stressed due to its higher correlation with general health in all waves than the question on limiting daily activities as a result of emotional problems. For parsimony, we focus our investigation by using data from the baseline (Wave 1) and 21 months (Wave 4) surveys. Table 1 gives details on how both variables are measured and their weighted distribution. The measure for asylum determination time was derived from the 'Time in UK' variable. Respondents were asked in the baseline questionnaire "In total, how long have spent living in the UK?"

No known data are available about the length of time individuals reside in the UK before putting in an asylum claim. The UK Government department with responsibility for asylum state that individuals must claim asylum on arrival (Home Office, 2020). However most asylum seekers do not follow this instruction partly as they are unaware of the rule but also because they are told by traffickers to wait until they are "in-country". In addition, many asylum seekers by necessity travel with false documentation, the possession of which is a criminal offence that can be used to refuse refugee status. Thus the majority of claims are not made "at port" but in the days and weeks after arrival (Right to Remain, 2016). Assuming the majority of asylum claims are made close to arrival, the 'time in the UK' variable essentially captures the length of time refugees wait for their asylum claim to be processed. Recognising the importance of swift decision-making the Government target around the time when SNR was conducted was to process asylum claims within six months. The "Time in UK" question was coded as an ordinal variable from "less than six months" to "five years or more". We hypothesise a negative association between longer asylum waiting time and refugee health status at time of grant and that this negative link persists post-settlement (21 months later). We also hypothesise that women fare worse than men and that religion has a moderating effect on poor self-reported health status.

\section{Ethics}

Our study is based on secondary analysis of the SNR data set. Full ethical approval was granted by the ethics review committee at the University of Birmingham prior to commencement of data analysis. This study was considered low risk because all identifiable characteristics of respondents had been removed before the dataset was deposited in the UK Data Service (UKDS). The SNR is licensed under the 'safeguarded' category with low risk of disclosure. The anonymised micro-data file was downloaded from UKDS after registration of the research project under the End User Licence.

\section{Statistical Analysis}

Our two outcome variables are emotional and physical health. The key predictors are asylum waiting time, gender and religion. All statistical models controlled for a range of confounders that could be associated with health: pre-arrival years of education, age, region of origin country, English fluency ${ }^{\mathrm{i}}$, 
whether respondents lived with a partner and dependent children under 18 at Wave 1 . The Wave 4 analysis also includes employment and victims of verbal or physical attack as controlled variables. ${ }^{\text {ii }}$ Given the evidence outlined above we hypothesise that:

H1 Length of time individuals wait for a final asylum decision increases their likelihood of reporting emotional and physical health problems at the time of grant

H2 This negative link between asylum waiting time and health status persists post settlement.

$\mathrm{H} 3$ The association between poor health and waiting time will be stronger among female refugees than men

H4 Religion ameliorates the negative association between waiting time and health.

\section{Table 1 about here}

Our analysis began with an overview of respondents' characteristics (Table 1) and the patterns of the relationship between our key predictor of interest: waiting time and refugee health (Figure 1). We then fitted ordinal logistic regression models to estimate the effects of asylum waiting time, gender and religion in determining refugees' self-reported emotional and physical health at Wave 1 and Wave 4. Table 2 presents the odds ratios and standard errors of pooled sample analysis for all respondents to ascertain if there is a statistically significant gender difference in both self-reported health statuses. For parsimony, waiting time is treated as a continuous variable. Table 3 presents the results of separate regression models for women and men at Wave 1. This allows us to assess the link between asylum waiting time and health for men and women independently. At times, the term 'effect' is used when reporting statistical findings to denote associations but not causality. To adjust for attrition bias, crosssectional weights are applied for Wave 1 models and longitudinal weights for Wave 4 models. To test the effect of attrition bias in the SNR, researchers have conducted rigorous analysis using Multiple Imputation (MI) techniques and compared the results with those using survey weights. They found that methods using available cases may have underestimated improvement in refugee health and well-being. However, they also found that the MI results were not significantly different from results using longitudinal weights, including results on reporting poor health (Rouxel and Chandola, 2018).

\section{Results}

As can be seen in Table 1, women refugees consistently report poorer emotional health. Twenty-five percent of male refugees compared to only 16 percent of women reported they were not at all bothered by emotional problems. At the same time, 13.6 percent of female refugees reported they were extremely bothered by emotional health problems compared with just 8.6 percent of men. The gendered patterns for physical health are remarkably similar with much higher proportions of female refugees reporting poorer health. Although female refugees were more likely (38 percent) to have dependent children under aged 18 living with them at grant of status compared to 17 percent of men, they were less likely (17 percent) to be living with a partner compared to 22 percent of men. In the third follow-up survey 21 months later, 61 percent of male refugees were in some kind of employment compared to only 25 percent of women. When it comes to experience of discrimination, 8.6 per cent of female refugees and 11.9 percent of their male counterparts reported they had been a victim of verbal or physical attack. It is widely known that access to good work and training are associated with better health and well-being (Wood et al., 2019). On the other hand, being a victim of attack or discrimination could lead to poorer mental and physical well-being (Cheung and Phillimore, 2017).

\section{Figure 1 about here}

Figure 1 shows that the percentage of reporting poor or very poor emotional health generally increases with longer asylum waiting time for both male and female refugees. At the time of grant (baseline survey), the longer the wait the worse the emotional health for both genders. Female refugees have higher percentages of reporting poor emotional and physical health compared to men although the 
difference in the latter is smaller. Female refugees with the longest waiting time (i.e. five years of more) have the highest percentage of reporting poor emotional and physical health.

To formally test our hypotheses, we moved on to ordinal logistic regression. The outcome variables are emotional and physical health, both are measured on a 5-point Likert Scale from very poor (5) to very good (1). All statistical models controlled for age, pre-arrival education, English fluency, region of their origin country, partner status and dependent children. Employment and victim of attack were controlled for in Wave 4 models only because asylum seekers were not permitted to work and these questions were not asked at Wave 1. Waiting time is treated as a continuous scale with "six months of less" being the lowest value and "five years or more" the highest.

Results from the pooled sample analysis for both genders in Table 2 show a significant effect of waiting time on both health statuses at Wave 1. The odds of self-reported poor emotional and physical health increase by a factor of 1.04 and 1.07 for each point of increase on the waiting time scale. Refugees who have spent longer than six months in the UK were significantly more likely to report poorer emotional and physical health at the time of grant, showing a clear link between waiting time and health thus supporting hypothesis 1 . The effect of waiting time is found to persist 21 months later at Wave 4 for emotional health $(\mathrm{OR}=1.13 \mathrm{p}<0.05)$. Similar results can be observed for physical health if only marginally significant $(\mathrm{OR}=1.08 \mathrm{p}<0.07)$. Hypothesis 2 is therefore partially supported.

\section{Table 2 about here}

Evidence on gender difference was unequivocal. Female refugees were significantly more likely than men to report poorer emotional $(\mathrm{OR}=1.85, \mathrm{p}<.001)$ and physical health $(\mathrm{OR}=1.81, \mathrm{p}<.001)$ at the time of grant. A persistent significant association was also found 21 months later. The odds for female refugees to report poor emotional health remains 1.45 higher compared to men and 1.66 higher for physical health, thus supporting hypothesis 3 . To formally examine if the effect of asylum waiting time on health varies by gender, we carried out a further test using an interaction term between gender and waiting time. The results show that longer waiting time is significantly associated with greater odds of reporting poorer emotional health for female refugees at time of grant $(\mathrm{OR}=1.10, \mathrm{p}<.01)$ and marginally for physical health $(\mathrm{OR}=1.18, \mathrm{p}<.08)$. These findings are confirmed in the separate models by gender in Table 3. The results showed that male refugees' emotional health at the time of grant was not associated with waiting time, and the results on this association with physical health was also only marginally significant. However, the evidence on female refugees is compelling. Those who spent a longer time living in the UK while waiting for their asylum decision were significantly more likely to report poorer emotional $(\mathrm{OR}=1.14, \mathrm{p}<.001)$ and physical health $(\mathrm{OR}=1.13, \mathrm{p}<.001)$ at the time of grant.

\section{Table 3 about here}

The evidence on religion's ameliorating role is mixed. Christians (40\%) and Muslims (48\%) make up the majority of the SNR sample. We use the largest group Muslims as the reference category in the regression model. Refugees with no religion were not significantly different from Muslims in either emotional or physical health. Therefore religion per se does not appear to have any ameliorating effect against poor physical health at time of grant in the pooled sample analysis (Table 2). The only exception was Christians who were significantly less likely to report poor emotional health at baseline $(\mathrm{OR}=0.85$, $\mathrm{p}<.001)$ compared to Muslim refugees. To formally test if religion ameliorates the negative association between waiting times and health, we fitted an interaction term between religion and waiting time. While Muslims reported poorer emotional and physical health compared to Christians at both points $(\mathrm{OR}=0.34$ and $0.55, \mathrm{p}<.001$ at Wave 1 ; and at Wave 4: $\mathrm{OR}=0.38$ and $0.33 \mathrm{p}<.001)$, the effect of waiting time on emotional and physical health for Muslim is actually positive compared to Christian $(\mathrm{OR}=1.39$ and $1.20, \mathrm{p}<.01)$. The same pattern is found 21 months later at Wave 4. Muslims reported poorer emotional health $(\mathrm{OR}=0.38, \mathrm{p}<.01)$ and physical health $(\mathrm{OR}=0.33, \mathrm{p}<.01)$. However, the effect of waiting time for both outcomes are positive for Muslims $(\mathrm{OR}=1.31$ and $1.32 \mathrm{p}<.03)$. This mixed 
finding suggests even though overall Muslims reported poorer emotional and physical health, the negative association between waiting time and health is far worse for Christians. Hypothesis four is therefore only partially supported in that the ameliorating role of religion does not operate in a linear fashion across the board.

In terms of other known factors predicting positive health and well-being, we controlled for employment and victim of attack at Wave 4 . Being a victim of attack significantly increases the odds of reporting poorer emotional and physical health $(\mathrm{OR}=2.68$ and 1.73$)$. Refugees in employment, as expected, were significantly less likely to report poor physical health but not emotional health. Above all, controlling for all these important confounders, our results still show a significant effect of waiting time, net of all these other effects in the statistical models.

\section{Discussion}

Our findings support the claims made by Grace et al. (2018) that policies of uncertainty, as played out in the UK through lengthy asylum waiting times spent in difficult conditions unable to work or study, are associated with physical and emotional harms. Our findings indicate a clear connection between the length of time in which refugees wait for a decision and their health, with emotional health most profoundly affected. This significant link persists 21 months post-settlement with refugee women experiencing more harm than men regardless of waiting period. Work by Ahmad et al. (2020) showed that Syrian resettlement refugees experienced increased depression over time which may have been associated with unemployment and experiences of racism. Although we find an association between being employed and racist attack and emotional health, when we control for these factors the association between waiting time and emotional health remains. Thus waiting time is important in determining emotional health even 21 months beyond a positive decision regardless of employment status.

Gender is a crucial factor in our findings. While women do report higher levels of psychological problems than men in the general and refugee populations the strength of association between gender and waiting times and both emotional and physical health is substantial. Menjívar and Perreira (2019) refer to cumulative violence and trauma that occur across the refugee journey highlighting an accumulation of adversities and disadvantages over time and place with gender being a key dimension in inequality. The particularities of women's forced migration and asylum seeking experiences and how these relate to short and long term health once in refuge require further investigation.

The effect of religion was mixed failing to convincingly support existing claims about the role of religion in building the resilience of refugees (Veronese et al., 2019). It is not clear why waiting time has less of a negative association with health for Muslims than Christians. However the SNR merely records individuals' religious identity and not the extent to which they practice their religion. It is possible, as has been identified elsewhere, that the protective effect of religion is evident only for individuals who engage in religious practice such as prayer (Halcon et al., 2004) and that our findings can be explained by the Muslim cohort being more likely to practice their religion than the Christians. Further investigation is needed to explain this association.

Our findings offer the first systematic evidence of the connection between waiting within asylum procedures and harm reported by refugees. They suggest that policies of uncertainty which keep asylum seekers waiting in a state of limbo while residing in poor conditions without the benefits of work or education and separated from friends and family have a longer-term human cost. Given the relationship between health status and integration indicators such as ability to work, develop social connections and learn a language (Cheung and Phillimore, 2013; 2014; 2017) we suggest these policies and the harm with which they are associated have potential to undermine the integration of those to whom states have agreed to grant refuge. Clearly more work is needed which should entail the collection of data to assess the actual health status of asylum-seekers, refugees and others subject to such uncertainty. Future studies might ask new refugees how long they waited for a positive decision, identify how many refusals were received, how many periods of destitution were experienced and whether or not individuals were 
detained to examine which of these factors is associated with health status. Further studies might also include measures of actual health rather than relying on self-assessment. While there is an existing body of work looking at the relationship between asylum seeking and psychological health (i.e. Sourander 2003) there is a dearth of knowledge about associations with physical health. Much more research is needed to explore the relationship between asylum process and physical health and looking at relations between asylum living conditions and regulations (i.e. whether study is possible) and health. Such work might include comparison of health outcomes between different policy contexts. More focus is needed on gender differences too and on unpacking associations between different kinds of refugee experience, for example sexual and gender based violence, waiting and health.

\section{Limitations}

Sample attrition of the SNR means the sample size fell to 939 in the last wave. To address non-response and attrition bias we followed standard procedures and apply cross-sectional and longitudinal weights where appropriate (Cebulla et al., 2010). As stated previously, results using longitudinal weights were not significantly different from those using multiple imputations. Refugees with better health and wellbeing were more likely to be missing from longitudinal surveys. Younger refugees may be also more likely to move to another city for work (Rouxel and Chandola, 2018). The SNR only asked the standard self-reported health question using four items from the SF-8 but not actual health outcome. Importantly, the SNR only enables us to measure the effects of waiting on those individuals who received some kind of refugee status. We know nothing about the effects on individuals whose claims are unsuccessful, and those who are subject to multiple asylum appeals, destitution and detention. Evidence from studies with failed asylum seekers suggest that levels of harm will be worse for these groups and would bear detailed investigation (see Mueller et al., 2011). Respondents in the SNR come from over 100 different countries, the largest groups being Eritreans (17 percent) and Somalians (16 percent), followed by Iraqis and Iranians ( 9 and 8 percent). Unless we only study the bigger groups, the sample size of individual country of origin is too small for regression analyses. Countries were therefore grouped together as regions in the statistical models. While the results show refugees from Africa reporting better health at grant compared to their peers from the Middle-East, we are mindful not to over-interpret these findings since it risks homogenising their vastly different experiences.

\section{Conclusions}

Grace et al.'s claims of a connection between state policies of waiting-related uncertainty and asylumseeker and refugee health are empirically supported by our analysis. The evidence we offer shows significant negative associations between extended periods of waiting-related uncertainty generated by lengthy and punitive asylum processes in the UK and health. Given the close association between our analysis, existing theory and results from qualitative studies and the wide use of policies of uncertainty in the Global North, our work is suggestive of likely generalisability. Thus, other countries with large refugee populations might want to take our findings into account when developing asylum policy and thinking about the implications of those policies for wider goals around refugee integration. Further work is needed to examine the relationship between waiting-related uncertainty and refugee and asylum-seeker health in countries with different asylum policies and practices. The need for such research is more pertinent now than ever during the global pandemic. Many countries have placed both asylum processes and resettlement schemes on hold and are housing applicants indefinitely in overcrowded, make-shift accommodation potentially generating harms with long-term consequences. Overall it is important to understand the effects of policies of waiting-related uncertainty on refugees' emotional and physical health, in particular how they vary by gender, when they reach the end of their journey and how these add a further layer of disadvantage undermining life chances in the short and long-term. 


\section{Acknowledgement:}

The authors would like to thank Nuffield Foundation for the grant received to undertake the initial analysis of the Survey of New Refugees. They also wish to acknowledge the helpful comments of the anonymous reviewers and Professors Paul Montgomery and Hajo Zeeb.

\section{References:}

Afifi, T.D., Afifi, W.A., Callejas, M.A., Shahnazi, A., White, A., Nimah, N., 2018. The functionality of communal coping in chronic uncertainty environments: The context of Palestinian refugees in Lebanon. Health Communication.

Ahmad, F., Othman, N., Hynie, M., Bayoumi, A.M., Oda, A., McKenzie, K., 2020. Depression-level symptoms among Syrian refugees: findings from a Canadian longitudinal study. Journal of Mental Health. 1-9. https://doi.org/10.1080/09638237.2020.1765998

Auyero, J., 2011. Patients of the state: An ethnographic account of poor people's waiting. Latin American Research Review. 46, 5-29.

Babatunde-Sowole, O., Power, T., Jackson, D., Davidson, P.M., DiGiacomo, M., 2016. Resilience of African migrants: An integrative review. Health care for women international. 37 (9), 946-963.

Biehl, K.S., 2015. Governing through uncertainty: Experiences of being a refugee in Turkey as a country for temporary asylum. Social Analysis. 59 (1), 57-75.

Bjertrup P.J., Bouhenia M., Mayaud P., Perrin C., Ben Farhat J., Blanchet K., 2018. A life in waiting: Refugees' mental health and narratives of social suffering after European Union border closures in March 2016. Social Science and Medicine. 215, 53-60.

Blackmore R., Boyle J.A., Fazel M., Ranasinha S., Gray K.M., Fitzgerald G., et al., (2020) The prevalence of mental illness in refugees and asylum seekers: A systematic review and meta-analysis. PLoS Med. 17 (9), e1003337. https://doi. org/10.1371/journal.pmed.1003337

Borges, G.M. and Faria, R., 2020. Breathing Under Water: Gendering the Violence Against Refugee Women. In Globalization and Its Impact on Violence Against Vulnerable Groups. IGI Global, pp. 125

Bourdieu, P., (2000) Pascalian meditations. Stanford, CA, Stanford University Press.

Brekke, J.P., 2004. While we are waiting: Uncertainty and empowerment among asylum-seekers in Sweden. Institutt for Samfunnsforskning. Report 10.

Bronstein, I., Montgomery, P., Ott, E., 2013. Emotional and behavioural problems amongst Afghan unaccompanied asylum-seeking children: results from a large-scale cross-sectional study. European Child \& Adolescent Psychiatry 22, 285-294.

Cange, C.W., Brunell, C., Acarturk, C., Fouad F.M., 2019. Considering chronic uncertainty among Syrian refugees resettling in Europe. The Lancet Public Health 4, e14.

Canning, V., 2017. Gendered harm and structural violence in the British asylum system. Milton Park: Taylor \& Francis.

Cebulla, A., Daniel, M., Devine, C., Tipping, S., 2010. Survey of New Refugees: Technical Notes. London: HMSO. 
Chase, E., 2020. Transitions, capabilities and wellbeing: how Afghan unaccompanied young people experience becoming 'adult' in the UK and beyond. Journal of Ethnic and Migration Studies. 46 (2), 439-456.

Cheung, S.Y. and Phillimore, J., 2013. Research Report for Nuffield Foundation. April 2013.

Cheung, S.Y., Phillimore, J., 2014. Refugees, Social Capital and Labour Market Integration in the UK. Sociology. 48, 518-536.

Cheung, S.Y., Phillimore, J., 2017. Gender and Refugee Integration: a Quantitative Analysis of Integration and Social Policy Outcomes. Journal of Social Policy. 46, 211-230.

Cleveland, J., Kronick, R., Gros, H., Rousseau, C., 2018. Symbolic violence and disempowerment as factors in the adverse impact of immigration detention on adult asylum seekers' mental health. International Journal of Public Health. 63, 1001-1008.

Dupont, H.J.B.H.M., Kaplan, C.D., Verbraeck, H.T., Braam, R.V., van de Wijngaart, G.F., 2005. Killing time: drug and alcohol problems among asylum seekers in the Netherlands. International Journal of Drug Policy. 16, 27-36.

Fleay, C., Hartley, L., 2016. 'I Feel Like a Beggar': Asylum Seekers Living in the Australian Community Without the Right to Work. Journal of International Migration and Integration. 17, 1031-1048.

Grace, B.L., Bais, R., Roth, B.J., 2018. The Violence of Uncertainty - Undermining Immigrant and Refugee Health. New England Journal of Medicine. 379, 904-905.

Griffiths, M.B., 2014. Out of time: The temporal uncertainties of refused asylum seekers and immigration detainees. Journal of Ethnic and Migration Studies. 40, 1991-2009.

Halcon, L.L., Robertson, C.L., Savik, K., Johnson, D.R., Spring, M.A., Butcher, J.N., Westermeyer, J.J., \& Jaranson, J.M., 2004. Trauma and Coping in Somali and Oromo Refugee Youth. Journal of Adolescent Health. 35, 17-25.

Home Office, 2005. Integration Matters A National Strategy for Refugee Integration. London: Home Office.

Home Office, 2008. Moving on together: Governments recommitment to supporting refugees. London: Home Office.

Home Office, UK Border Agency Analysis. Research and Knowledge Management, 2010. Survey of New Refugees 2005-2009 [Internet]. London: UK Data Service [cited 2019 July 17]; Available from: http://doi.org/10.5255/UKDA-SN-6556-1

Home Office, 2021. Immigration Statistics Asylum and Resettlement - outcome analysis of asylum applications - 25th February 2021.

Ingvarsson, L., Egilson, S.T., Skaptadottir, U.D., 2016. "I want a normal life like everyone else": Daily life of asylum seekers in Iceland. Scandinavian Journal of Occupational Therapy. 23, 416-24.

Kuehner, C., 2016. Why is depression more common among women than among men?. Lancet Psychiatry. (published online Nov 14.) http://dx.doi.org/10.1016/S2215-0366(16)30263-2 
Laban, C.J., Gernaat H.B.P.E., Komproe I.H., van der Tweel I., De Jong J.T.V.M., 2005.

Postmigration living problems and common psychiatric disorders in Iraqi asylum seekers in the Netherlands. Journal of Nervous and Mental Disease. 193, 825-832.

Laban, C.J., Komproe I.H., Gernaat H.B.P.E., De Jong J.T.V.M., 2008. The impact of a long asylum procedure on quality of life, disability and physical health in Iraqi asylum seekers in the Netherlands. Social Psychiatry and Psychiatric Epidemiology. 43, 507.

Lamkaddem, M., Essink-Bot M-L., Devillé W., Gerritsen A., Stronks K., 2015. Health changes of refugees from Afghanistan, Iran and Somalia: the role of residence status and experienced living difficulties in the resettlement process. European Journal of Public Health. 25, 917-922.

Lauritzen, C, Sivertsen H., 2012. Children and Families Seeking Asylum in Northern Norway: Living Conditions and Mental Health. International Migration 50, 195-210.

Lentin, A., 2004. Racism and Anti-racism in Europe. Chicago: Pluto Press.

Li, S., Bronwyn, M. and Graham, B. 2016. Why are women so vulnerable to anxiety, trauma-related and stress-related disorders? The potential role of sex hormones. Lancet Psychiatry.

http://dx.doi.org/10.1016/S2215-0366(16)30358-3

Lyons, K., 2018. Revealed: asylum seekers' 20-year wait for Home Office ruling https://www.theguardian.com/uk-news/2018/aug/17/revealed-asylum-seekers-20-year-wait-for-homeoffice-ruling

Mayblin, L., Wake, M., Kazemi, M., 2020. Necropolitics and the slow violence of the everyday: Asylum seeker welfare in the postcolonial present. Sociology. 54 (1), 107-123.

Menjívar, C., Perreira, K.M., 2019. Undocumented and unaccompanied: children of migration in the European Union and the United States, Journal of Ethnic and Migration Studies, 45, 197-217.

Mueller, J., Schmidt, M., Staeheli, A., Maier, T., 2011. Mental health of failed asylum seekers as compared with pending and temporarily accepted asylum seekers. European Journal of Public Health. 21 (2), 184-189.

Phillimore, J., Pertek, S., Akyuz, S. Darkal, H., and Hourari, J. (2021) “We are forgotten”: Forced migration, sexual and gender-based violence and COVID-19. Violence Against Women.

Phillimore, J., Goodson, L., 2006. Problem or opportunity? Asylum seekers, refugees, employment and social exclusion in deprived urban areas. Urban Studies. 43 (10), 1715-1736.

Phillips, D., 2006. Moving towards integration: the housing of asylum seekers and refugees in Britain. Housing Studies. 21 (4), 539-553.

Reesp S., 2003. Refuge or retrauma? The impact of asylum seeker status on the wellbeing of East Timorese women asylum seekers residing in the Australian community. Australasian Psychiatry. 11 (sup1), S96-S101.

Refugee Action, 2018. Waiting in the Dark: How the asylum system dehumanises, disempowers and damages. https://www.refugee-action.org.uk/wp-content/uploads/2020/07/Waiting-in-the-DarkReport.pdf

Right to Remain (2016) Entering the UK and claiming asylum. https://righttoremain.org.uk/enteringuk-and-claiming-asylum/ 
Rotter, R., 2016. Waiting in the asylum determination process: Just an empty interlude? Time \& Society. 25 (1), 80-101.

Rouxel, P., Chandola, T., 2018. What are the wider social determinants of refugee health and wellbeing? Some methodological considerations. Conference paper for Symposium on Refugees Settlement and Wellbeing over the Life Course. Brisbane: University of Queensland. May 21.

Schoretsanitis, G., Bhugra, D., Eisenhardt S., Ricklin, M.E., Srivastava, D.S., Exadaktylos, A. Sourander A., 2003. Refugee families during asylum seeking. Nordic Journal of Psychiatry. 57, 203207.

Turnbull S., 2016. 'Stuck in the middle': Waiting and uncertainty in immigration detention. Time \& Society. 25, 61-79.

Veronese, G., Pepe, A., Sala, G., Vigliaroni, M., 2019. Measuring subjective well-being in an understudied population of young Western-African IDPs and refugees. International Journal of Migration, Health and Social Care.

Walsh, P. (2020) Asylum and refugee resettlement in the UK. Oxford: Migration Observatory.

Williams, A.M., Baláž, V., 2012. Migration, risk, and uncertainty: Theoretical perspectives. Population, Space and Place. 18 (2), 167-180.

Women's Refugee Commission (2016) Protection Risks for Women and Girls in the European Refugee and Migrant Crisis. http://www.womensrefugeecommission.org/research-resources/

Wood, N., Charlwood, G., Zecchin, C., Hansen, V., Douglas, M., Pit, S.W., 2019. Qualitative exploration of the impact of employment and volunteering upon the health and wellbeing of African refugees settled in regional Australia: a refugee perspective. BMC Public Health. 19 (1), 1-15.

Wu, S., Ellingson, S., Hagstrom, P., Kucinskas, J., 2020. Religion and Refugee Well-Being: The Importance of Inclusive Community. Journal for the Scientific Study of Religion.

https://doi.org/10.1111/jssr.12702 


\section{Table 1: Variable Description and Descriptive Statistics *}

Emotional Health: During the past 4 weeks, how much have you been bothered by emotional problems (such as feeling worried, depressed or stressed)?

Variable

Original codes

\section{Recoded into}

\begin{tabular}{cc}
\multicolumn{2}{c}{ Wave $1 \%$} \\
\multicolumn{2}{c}{$\mathbf{N}=5480 \dagger$} \\
Women & Men \\
15.8 & 24.9 \\
18.5 & 21.7 \\
21.6 & 22.2 \\
30.6 & 22.5 \\
13.6 & 8.7
\end{tabular}

\begin{tabular}{cc}
\multicolumn{2}{c}{ Wave $\mathbf{4 \%}$} \\
\multicolumn{2}{c}{$\mathbf{N}=\mathbf{8 4 9} \dagger$} \\
Women & Men \\
24.3 & 30.8 \\
29.3 & 28.6 \\
14.3 & 15.2 \\
23.8 & 17.2 \\
8.3 & 6.2
\end{tabular}

Physical Health: During the past 4 weeks, how much did physical health problems limit what you would usually do each day? e.g. finding work/housing, attending school, socialising with friends, etc.

\section{Variable}

Wave 1:

Q34_limit_phyhealth

Wave 4:

f3q40_phys_limit

\section{Original codes}

Not at all

Very Little

Somewhat

Quite a lot

Could not do daily activities

\section{Recoded into}

1 Very Good
2 Good
3 Fair
4 Poor
5 Very Poor

1 Very Good

3 Fair

5 Very Poor

\begin{tabular}{cc}
\multicolumn{2}{c}{ Wave $\mathbf{1} \%$} \\
$\mathbf{N}=5480 \dagger$ \\
Women & Men \\
34.5 & 48.2 \\
21.7 & 20.9 \\
19.4 & 14.9 \\
17.9 & 12.2 \\
6.6 & 3.9
\end{tabular}

Women

29.4

19.4

11.5

22.4

17.3

26.1

43.5

18.3

Living with Spouse - Yes

Dependent Children under 18 - Yes

3. Middle East

4. Asia

English Proficiency (average scores on 1-4 Scale)

Wave 4 [N=937]

English Proficiency (average scores on 1-4 Scale)

Percentages may not add up to 100 due to rounding.

$\dagger$ Sample Ns are weighted using cross-sectional weights at Wave 1 (basewght) and at Wave 4 (f3_weight). 
Figure 1: Percentage reporting Poor/Very Poor Emotional and Physical Health by Sex and Asylum Waiting Time

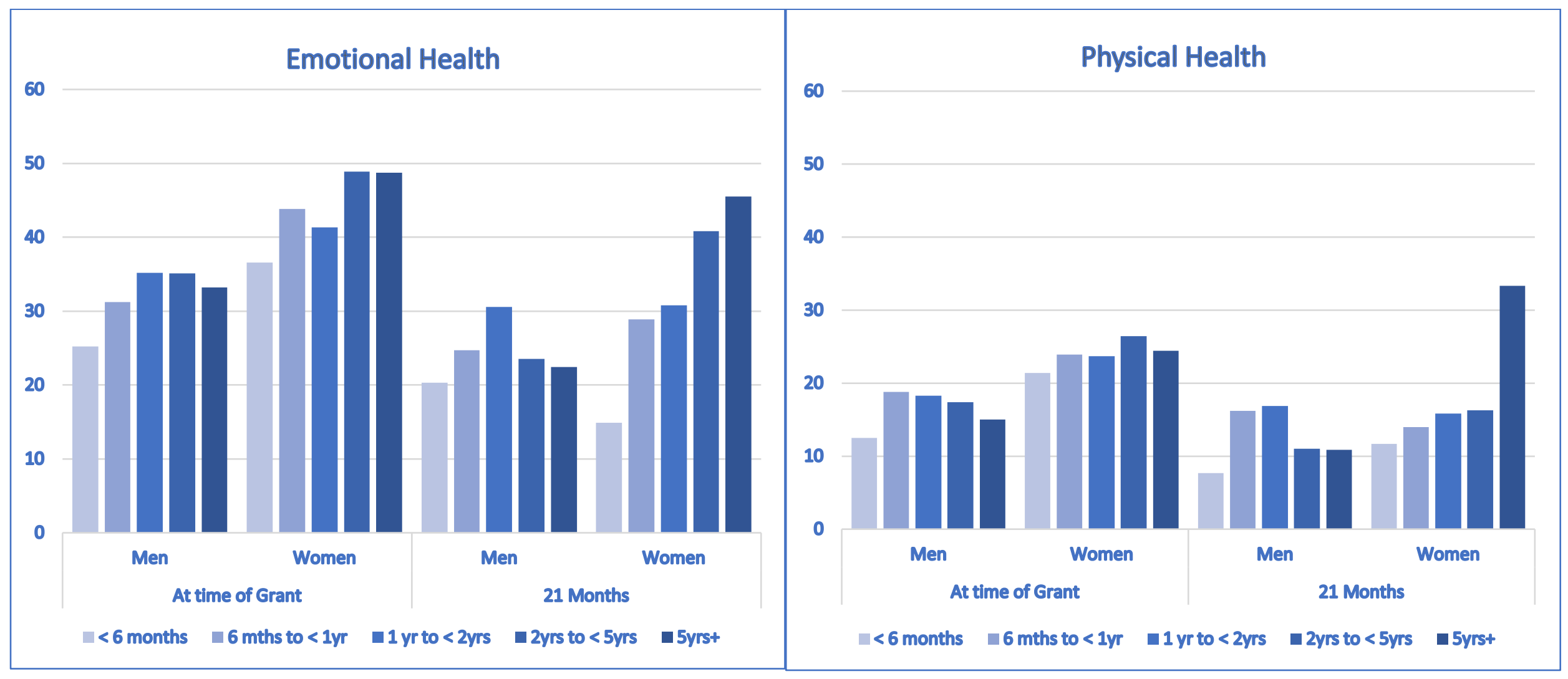




\section{Table 2: Pooled Samples Ordinal Logistic Regression Results for Poor Emotional and Physical Health at Wave 1 and Wave 4}

At time of Grant (Wave 1)

21 Months (Wave 4)

\begin{tabular}{|c|c|c|c|c|c|c|c|c|c|c|c|}
\hline & Emotional & (s.e.) & Physical & & (s.e.) & Emotional & & (s.e.) & Physical & & 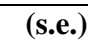 \\
\hline Female & $1.85 * * *$ & $(0.11)$ & 1.81 & $* * *$ & $(0.11)$ & 1.45 & $*$ & $(0.27)$ & 1.66 & $* *$ & $(0.33)$ \\
\hline Waiting Time & $1.04 *$ & $(0.02)$ & 1.07 & $* *$ & $(0.02)$ & 1.13 & $*$ & $(0.07)$ & 1.08 & & $(0.07)$ \\
\hline \multicolumn{12}{|l|}{ Religion } \\
\hline \multicolumn{12}{|l|}{ (Ref: Muslims) } \\
\hline Christian & $0.83 * * *$ & $(0.05)$ & 0.91 & & $(0.07)$ & 0.82 & & $(0.17)$ & 0.72 & & $(0.17)$ \\
\hline Other & 0.93 & $(0.11)$ & 1.07 & & $(0.12)$ & 0.67 & & $(0.26)$ & 0.50 & $\dagger$ & $(0.19)$ \\
\hline None & 0.91 & $(0.12)$ & 0.89 & & $(0.12)$ & 0.71 & & $(0.21)$ & 0.43 & $* *$ & $(0.15)$ \\
\hline \multicolumn{12}{|l|}{$\begin{array}{l}\text { Region of Origin } \\
\text { (Ref: Middle East) }\end{array}$} \\
\hline Asia & $0.76 \quad * * *$ & $(0.08)$ & 0.92 & & $(0.09)$ & 0.80 & & $(0.24)$ & 0.91 & & $(0.26)$ \\
\hline America/Europe & 1.01 & $(0.10)$ & 1.01 & & $(0.10)$ & 1.52 & & $(0.41)$ & 1.08 & & $(0.32)$ \\
\hline \multicolumn{12}{|l|}{$\begin{array}{l}\text { Pre-arrival Education } \\
\text { (Ref: } 0-6 \text { years) }\end{array}$} \\
\hline $7-12$ years & $0.82 * *$ & $(0.06)$ & 1.03 & & $(0.08)$ & 1.17 & & $(0.33)$ & 0.84 & & $(0.22)$ \\
\hline 13 yearst & $1.34 * * *$ & $(0.11)$ & 1.13 & & $(0.10)$ & 1.36 & & $(0.36)$ & 0.67 & & $(0.17)$ \\
\hline English Fluency & 0.95 & $(0.03)$ & 0.71 & $* * *$ & $(0.03)$ & 0.86 & & $(0.10)$ & 0.84 & & $(0.11)$ \\
\hline In employment (W4) & & & & & & 0.80 & & $(0.15)$ & 0.60 & $* *$ & $(0.11)$ \\
\hline Victim of attack (W4) & & & & & & 2.68 & $* * *$ & $(0.62)$ & 1.73 & $* *$ & $(0.37)$ \\
\hline
\end{tabular}

$* * * \mathrm{p}<001 ; * * \mathrm{p}<01 ; * \mathrm{p}<05,+\mathrm{P}<10$. Robust standard errors are in parentheses.

Models controlling for age, partner status and dependent children under 18 (but not reported in table)

Wave 1 models are weighted with basewght and Wave 4 models with longitudinal weight wtl_b123. 
Table 3: Ordinal Logistic Regression Results for Women's and Men's Poor Emotional and Physical Health (Wave 1)

\begin{tabular}{|c|c|c|c|c|c|c|c|c|c|c|c|c|}
\hline & \multicolumn{6}{|c|}{ Emotional Health } & \multicolumn{6}{|c|}{ Physical Health } \\
\hline & Women & & (s.e.) & Men & & (s.e.) & Women & & (s.e.) & Men & & (s.e.) \\
\hline Waiting Time & 1.14 & $* * *$ & $(0.04)$ & 1.02 & & $(0.02)$ & 1.13 & $* * *$ & $(0.04)$ & 1.05 & $\dagger$ & $(0.03)$ \\
\hline \multicolumn{13}{|l|}{$\begin{array}{l}\text { Religion } \\
\text { (Ref: Muslims) }\end{array}$} \\
\hline Christian & 0.73 & $* *$ & $(0.08)$ & 0.87 & $\dagger$ & $(0.07)$ & 1.04 & & $(0.11)$ & 0.82 & $*$ & $(0.07)$ \\
\hline Other & 0.69 & $\dagger$ & $(0.15)$ & 1.13 & & $(0.16)$ & 0.94 & & $(0.18)$ & 1.17 & & $(0.16)$ \\
\hline None & 0.88 & & $(0.20)$ & 0.94 & & $(0.14)$ & 1.11 & & $(0.30)$ & 0.83 & & $(0.13)$ \\
\hline \multicolumn{13}{|l|}{$\begin{array}{l}\text { Region of Origin } \\
\text { (Ref: Middle East) }\end{array}$} \\
\hline Africa & 0.60 & $* * *$ & $(0.09)$ & 0.78 & $* *$ & $(0.07)$ & 0.51 & $* * *$ & $(0.07)$ & 0.80 & $* *$ & $(0.08)$ \\
\hline Asia & 0.75 & & $(0.14)$ & 0.68 & $* *$ & $(0.09)$ & 0.75 & $\dagger$ & $(0.12)$ & 0.95 & & $(0.12)$ \\
\hline America/Europe & 1.27 & & $(0.25)$ & 0.85 & & $(0.10)$ & 0.86 & & $(0.16)$ & 1.04 & & $(0.13)$ \\
\hline \multicolumn{13}{|l|}{$\begin{array}{r}\text { Pre-arrival Education } \\
\text { (Ref: } 0-6 \text { years) }\end{array}$} \\
\hline $7-12$ years & 0.90 & & $(0.11)$ & 0.79 & $* *$ & $(0.07)$ & 0.99 & & $(0.12)$ & 1.07 & & $(0.10)$ \\
\hline 13 years+ & 1.25 & & $(0.17)$ & 1.38 & $* *$ & $(0.14)$ & 0.89 & & $(0.12)$ & 1.28 & $*$ & $(0.14)$ \\
\hline English Fluency & 0.96 & & $(0.06)$ & 0.92 & $\dagger$ & $(0.04)$ & 0.69 & $* * *$ & $(0.04)$ & 0.71 & $* * *$ & $(0.03)$ \\
\hline $\mathbf{N}$ & \multicolumn{3}{|c|}{1835} & \multicolumn{3}{|c|}{3290} & \multicolumn{3}{|c|}{1819} & \multicolumn{3}{|c|}{3271} \\
\hline
\end{tabular}


'English fluency is measured by taking the mean of the sums of scores of respondents' ability to understand, speak, read and write English on a scale of 1 to 4.

ii Before controlling for confounders, 'Time in UK' had a highly significant negative association with refugee mental (OR=0.92) and physical health $(\mathrm{OR}=0.95)$ at Wave 1 . At Wave 4 , this negative association persists for emotional health (OR=0.87) but its association with physical health is not statistically significant $(\mathrm{OR}=0.92, \mathrm{p}<.0 .08)$. 